Check for updates

Lewisham and Greenwich NHS Trust, London, UK

anna.moore2@nhs.net Cite this as: BMJ 2021;375:n2385 http://dx.doi.org/10.1136/bmj.n2385 Published: 06 October 2021

\section{A planetary health curriculum for medicine}

\author{
Needed yesterday; make it a reality today \\ Anna Moore Health Education England population health fellow
}

Undergraduate medical curriculums are notoriously packed and space for new content is hotly contested. But what if there was a way that medical schools could ensure that students graduate with enhanced clinical knowledge, skills and competence and a deep understanding of health, as well as disease, by adding just one new theme?

That theme is of course planetary health. Health educators have been advocating for the inclusion of climate and environmental education in medical and nursing curriculums for the past two decades. ${ }^{1-6}$ In the UK, sustainable healthcare principles were included in the GMC's graduate outcomes in 2018, ${ }^{7}$ but medical schools have been slow to respond, and planetary health remains on the periphery of most curriculums.

Now, as the generation that will experience the most severe health effects of climate change, students are demanding action. ${ }^{89}$ This year a global study, led by students aiming to inspire engagement with planetary health, found that in 31 of the 33 UK medical schools, eight have no content related to planetary health, and a further five include only one lecture or session. No schools in the UK or Ireland scored above a B, using a consensus scoring system grading schools $\mathrm{A}+$ to $\mathrm{F}$ - based on performance in five areas (planetary health curriculum, interdisciplinary research, university support, community outreach, and sustainability). Internationally, the picture is not much better: only two of the 26 medical schools in the US and Canada scored above a B. ${ }^{10}$

We have no more time to wait for things to improve. The rapid escalation of the climate crisis means that knowledge, attitudes, and skills must shift rapidly in order to implement the changes needed in clinical and educational practice ${ }^{11}$ to reduce the climate impact of healthcare and improve health. Planetary health and sustainable healthcare show us the way, demonstrating the interdependence of health and ecosystems and giving us a framework for providing excellent healthcare both for individuals and for our ecosystem. ${ }^{.12}$

\section{New way of learning}

There are also educational benefits. By applying a planetary health lens to all clinical subjects, actively looking for links between ecosystems and health, we start to think critically about the healthcare systems we work in and see opportunities for improvement. Finding academic staff willing to teach this "new" subject is seen by many as a challenge, but viewed in a different way it presents an opportunity to shift medical education away from a top down model towards a participatory model, with students and staff learning in partnership. ${ }^{13} 14$
Let's imagine a week of endocrinology teaching in a medical undergraduate course with a cross cutting theme of planetary health and sustainable healthcare. Students learn that type 2 diabetes is a serious public health problem associated with huge costs to physical and mental health, on which $12.5 \%$ of the medicines budget is spent. ${ }^{15}$ The carbon cost of diabetes is also included, and students are reminded that medicines make up $25 \%$ of the NHS carbon footprint. ${ }^{11}$ Students already familiar with the health consequences of global heating ${ }^{16}$ now learn that people living with diabetes are particularly vulnerable to excessive heat and other climate change related threats. ${ }^{17}$

In a sociology session they learn about the disproportionate burden of diabetes and its complications on minoritised groups and those with higher levels of deprivation ${ }^{18}$ and the potential for social prescribing to counter this. ${ }^{19}$ They start to understand the social determinants of health-the "causes of the causes" of disease. ${ }^{20}$ Students' discussion with the lecturer centres around climate justice in relation to diabetes.

Teaching communication skills focuses on the importance of behaviour change in the prevention and management of diabetes and how to facilitate that change. ${ }^{21}$ The issue of "adherence" to medication is considered, and students learn that $30-50 \%$ of medicines prescribed for long term conditions are not taken as intended ${ }^{22}$ and that in the UK £3oom (€350m; \$400m) is spent on unused medicines every year. ${ }^{23}$ Applying the planetary health lens, the resulting harms to both people and planet of wasted medicines are explored. Students discuss the language around optimisation of medicines, preferring the term "concordance," ${ }^{24}$ and reflect that this approach is more likely to be successful in facilitating better diabetes control, which will in turn reduce waste and reduce environmental harm.

Finally, students attend a community diabetes clinic, and learn about managing diabetes from people with the condition. They write up a patient history and reflect on the relationship between diabetes, community, and environment. One student considers the climate impacts of causes of obesity, including diets rich in refined sugars, refined fats, oils, and meat $^{25}$ and car dependence causing physical inactivity and air pollution. ${ }^{26-28}$ Learning from this is added to the curriculum content for the following year.

By applying a planetary health and sustainable healthcare lens to all learning, medical students gain vital clinical skills, an appreciation of the interdependence of human health, healthcare and the environment, and experience of critical and 
systems thinking-having also contributed to the learning of their peers and lecturers along the way.

While this curriculum remains a vision for the future, our health suffers. Let's stop imagining and make it a reality now.

Competing interests: I have read and understood BMJ policy on declaration of interests and have no interests to declare.

Provenance and peer review: Commissioned; not externally peer reviewed.

1 Kirk $M$. The impact of globalization and environmental change on health: challenges for nurse education. Nurse Educ Today 2002;22:60-71, discussion 72-5.

doi: 10.1054/nedt.2001.0720. pmid: 11886231

2 Gómez A, Balsari S, Nusbaum J, Heerboth A, Lemery J. Perspective: Environment, biodiversity, and the education of the physician of the future. Acad Med 2013;88:168-72. doi: 10.1097/ACM.0b013e31827bfbeb. pmid: 23269293

3 Walpole SC, Mortimer F, Inman A, Braithwaite I, Thompson T. Exploring emerging learning needs: a UK-wide consultation on environmental sustainability learning objectives for medical education. Int J Med Educ 2015;6:191-200. doi: 10.5116/ijme.5643.62cd. pmid: 26702552

4 Walpole SC, Barna S, Richardson J, Rother HA. Sustainable healthcare education: integrating planetary health into clinical education. Lancet Planet Health 2019;3:e6-7.

doi: 10.1016/S2542-5196(18)30246-8. pmid: 30654868

5 Shaw E, Walpole S, McLean M, etal. AMEE consensus statement: planetary health and education for sustainable healthcare. Med Teach 2021;43:272-86. doi: 10.1080/0142159X.2020.1860207. pmid: 33602043

6 Tun MS. Fulfilling a new obligation: teaching and learning of sustainable healthcare in the medical education curriculum. Med Teach 2019;41:1168-77. doi: 10.1080/0142159X.2019.1623870. pmid: 31237167

7 General Medical Council. Outcomes for graduates 2018. 2018. https://www.gmc-uk.org/-/media/documents/dc11326-outcomes-for-graduates-2018_pdf-75040796.pdf

8 UK medical schools must teach about climate crisis, say students. Guardian 2-21 Aug 17. https://www.theguardian.com/environment/2021/aug/17/uk-medical-schools-must-teach-aboutclimate-change-say-students

9 Marill MC. Pressured by students, medical schools grapple with climate change.. Health Aff (Millwood) 2020;39:2050-5. doi: 10.1377/hlthaff.2020.01948. pmid: 33284698

10 Planetary Health Report Card. 2021. https://phreportcard.org/

11 NHS Net Zero Expert Panel. Delivering a "net zero" National Health Service. 2020. https:/www.england.nhs.uk/greenernhs/wp-content/uploads/sites/51/2020/10/delivering-a-netzero-national-health-service.pdf

12 Mortimer F. The sustainable physician. Clin Med (Lond) 2010;10:110-1. doi: 10.7861/clinmedicine.10-2-110. pmid: 20437974

13 Tun May Sanyu Tun S, Wellbery C, Teherani A. Faculty development and partnership with students to integrate sustainable healthcare into health professions education. Med Teach 2020;42:1112-8. doi: 10.1080/0142159X.2020.1796950. pmid: 32762586

14 Freire P. Chapter 2. In: Sheed W, ed. The pedagogy of the oppressed. Penguin Books, 1972:46-7.

15 NHS Digital. Prescribing for diabetes in England, 2008/09-2018/19. 2019. https://digital.nhs.uk/data-and-information/publications/statistical/prescribing-for-diabetes/2008-09---2018-19/resultsand-charts

16 Watts N, Amann M, Arnell N, etal. The 2020 report of the Lancet countdown on health and climate change: responding to converging crises. Lancet 2021;397:129-70. doi: 10.1016/S0140-6736(20)32290-X. pmid: 33278353

17 Zilbermint M. Diabetes and climate change. J Community Hosp Intern Med Perspect 2020;10:409-12. doi: 10.1080/20009666.2020.1791027. pmid: 33235673

18 Ogunwole SM, Golden SH. Social determinants of health and structural inequities and root causes of diabetes disparities. Diabetes Care2021;44:11-3. doi: 10.2337/dci20-0060. pmid: 33571949

19 Calderón Larrañaga S, Clinch M, Greenhalgh T, Finer S. Could social prescribing contribute to type 2 diabetes prevention in people at high risk? Protocol for a realist, multilevel, mixed methods review and evaluation. BMJ Open 2021;11:e042303. doi: 10.1136/bmjopen-2020-042303. pmid: 33837096

20 Marmot M. Inclusion health: addressing the causes of the causes. Lancet 2018;391:186-8. doi: 10.1016/S0140-6736(17)32848-9. pmid: 29137870

21 Rollnick S, Miller WR. What is motivational interviewing? Behavioral and cognitive psychotherapy. Behav Cogn Psychother 1995;23:325-34. doi: 10.1017/S135246580001643X.

22 NICE. Medicines optimisation. 2016. https://www.nice.org.uk/guidance/qs120

23 NHS England, Reader I, Hazell B, Robson R. Pharmaceutical waste reduction in the NHS. 2015:1-24. https://www.england.nhs.uk/wp-content/uploads/2015/06/pharmaceutical-waste-reduction.pdf

24 Chatterjee JS. From compliance to concordance in diabetes. J Med Ethics 2006;32:507-10. doi: 10.1136/jme.2005.012138. pmid: 16943329

25 Tilman D, Clark M. Global diets link environmental sustainability and human health. Nature 2014;515:518-22. doi: 10.1038/nature13959. pmid: 25383533

26 de Hartog J, Boogaard H, Nijland H, Hoek G. Do the health benefits of cycling outweigh the risks? Environ Health Perspect 2010;118:1109-16. doi: 10.1289/ehp.0901747. pmid: 20587380
27 Mayor of London. Health impacts of cars in London. 2015. https://www.london.gov.uk/sites/default/files/health_impact_of_cars_in_london-sept_2015_final_0.pdf

28 Douglas MJ, Watkins SJ, Gorman DR, Higgins M. Are cars the new tobacco?J Public Health (Oxf) 2011;33:160-9. doi: 10.1093/pubmed/fdrO32. pmid: 21610130 